\title{
Pioglitazone-induced increase of insulin sensitivity in the muscles of the obese Zucker fa/fa rat cannot be explained by local adipocyte differentiation
}

\author{
S.Hallakou ${ }^{1,2}$, F. Foufelle ${ }^{1}$, L. Doaré ${ }^{2}$, M. Kergoat ${ }^{2}$, P. Ferré ${ }^{1}$ \\ ${ }^{1}$ U465 INSERM, Centre de Recherches Biomédicales des Cordeliers, Paris, France \\ ${ }^{2}$ LIPHA Research Laboratory, Chilly-Mazarin, France
}

\begin{abstract}
Summary Thiazolidinediones are potent antidiabetic compounds, which act by enhancing peripheral insulin sensitivity. They are also activators of the peroxisome proliferator activated receptor $\gamma$ in adipose tissue. Pioglitazone induces in vivo adipocyte differentiation in the obese Zucker fa/fa rat and hence the capacity of adipose tissue to utilize glucose. Nevertheless, muscles are the major site for insulin-mediated glucose disposal. The increase of muscle glucose utilization under thiazolidinedione treatment could be secondary to local adipose tissue differentiation. This possibility is supported by the fact that a thiazolidinedione-induced myoblast conversion into adipocytes has been described in vitro. To address this problem, we have studied the in vivo effect of a pioglitazone treatment on insulin-induced glucose utilization and the expression of genes exclusively expressed in mature adipocytes in three muscles differing by their fibre composition in Zucker (fa/fa) rats.
\end{abstract}

Whereas pioglitazone treatment increased insulinstimulated glucose utilization to the same extent in all muscle types, an adipocyte differentiation was only present in the oxidative muscle, the soleus. Soleus muscle was also the only one in which the presence of genes specific for adipose tissue could be detected before the pioglitazone treatment. There was no detectable expression of adipocyte specific genes in the extensor digitorum longus or in the epitrochlearis muscles before or after the drug treatment. We conclude that pioglitazone effects on muscle glucose metabolism cannot be due to a local adipocyte differentiation, and that the conversion of myoblasts into adipocytes under thiazolidinedione stimulation observed in vitro is, if it exists, a marginal phenomenon in vivo. [Diabetologia (1998) 41: 963-968]

Keywords Thiazolidinedione, $\operatorname{PPAR} \gamma$, muscle, $\mathrm{Zu}-$ cker fa/fa rat, adipocyte differentiation, glucose utilization.
Thiazolidinediones (TZD) compounds have been developed in order to counteract the insulin resistance state observed in Type II diabetes mellitus [1]. Al-

Received: 22 December 1997 and in final revised form: 9 March 1998

Corresponding author: P. Ferré, U465 INSERM, Centre de Recherches Biomédicales des Cordeliers, 15 rue de l'Ecole de Médecine, 75270, Paris cedex 06, France.

Abbreviations: $\mathrm{C} / \mathrm{EBP} \alpha, \mathrm{CCAAT} /$ enhancer binding protein $\alpha$; EDL, Extensor digitorum longus; FAS, Fatty acid synthase; PEPCK, Phosphoenolpyruvate carboxykinase; PPAR, Peroxisome-proliferator-activated receptor; TZD, Thiazolidinedione. though TZD clearly enhance the peripheral sensitivity to insulin in human and animal models of insulin resistance, the precise mechanism of this effect is not known $[2,3]$. The elucidation of the mechanism of the action of TZD remains a major issue for their use in the treatment of Type II diabetes mellitus.

TZD are high affinity ligands of PPAR $\gamma$ (Peroxisome Proliferator Activated Receptor $\gamma$ ), a subtype of the nuclear receptor superfamily of ligand-activated transcription factors [4]. PPAR $\gamma$ is expressed at a high level in adipose tissue only [5] and is a key factor for the differentiation of this tissue $[6,7]$ and regulation of the expression of specific adipocyte genes (e.g. phosphoenolpyruvate carboxykinase [8]). Moreover, non-adipocyte precursors such as fibro- 
blasts or even myoblasts are able to respond in vitro to TZD by partial conversion into an adipocyte-like phenotype [9-11].

In a recent paper, we showed that a TZD compound, pioglitazone, markedly improves the glucose tolerance in an animal model of insulin resistance, the obese Zucker fa/fa rat [12]. Pioglitazone also strongly induced adipocyte differentiation and increased adipose tissue glucose utilization at post-absorptive insulin concentrations in vivo [12].

It is clearly established that muscles are the major site for insulin-mediated glucose disposal. Thus, this tissue must also be involved in the pioglitazone-induced increase in glucose disposal under insulin stimulation. However, since PPAR $\gamma$ is expressed mainly in adipose tissue, we hypothesize that part of the increase of muscle glucose utilization under pioglitazone is secondary to differentiation of adipocyte precursors or even myoblasts to adipose tissue.

In the present paper, we show that both oxidative and glycolytic muscles respond equally to a pioglitazone treatment by enhancing their insulin-stimulated glucose utilization, though an adipocyte differentiation was observed in an oxidative muscle only, probably from pre-existing preadipocytes. We conclude therefore that local adipocyte differentiation is not responsible for the pioglitazone effect on muscle glucose metabolism and that the TZD-induced differentiation of myoblasts to adipocytes observed in vitro is not a major effect in in vivo experiments.

\section{Materials and methods}

Animals. Animal studies were conducted according to the French Guidelines for the Care and Use of Experimental Animals. Female obese Zucker (fa/fa) rats were bred in our laboratory from pairs originally provided by the Harriet G. Bird Memorial Laboratory (Stowe, Mass., USA). The animals were maintained under a constant light-dark cycle (light from 07.00 hours to 19.00 hours) and given free access to chow pellets and water. The rats were treated by gavage with $10 \mathrm{mg} \cdot \mathrm{kg}^{-1} \cdot \mathrm{day}^{-1}$ of pioglitazone HCL (Lipha S. A., ChillyMazarin, France) each morning at 09.00 hours. A single daily dose was given to 12 -week-old rats for 28 days. In each case, the last dose of pioglitazone was given $2 \mathrm{~h}$ before the various experiments.

Measurement of glucose turnover rate and muscle glucose utilization in the basal state or under insulin stimulation. Experiments were performed at 11.00 hours on rats which were deprived of food for $2 \mathrm{~h}$ and treated or not with pioglitazone for 28 days. Rats were anaesthetized using pentobarbital. A catheter was inserted into one of the carotid arteries for blood sampling and a tracheotomy was performed. In the groups studied in basal insulin conditions, a primed $(7 \mu \mathrm{Ci})$ continuous $\left(0.2 \mu \mathrm{Ci} \cdot \mathrm{min}^{-1}\right)$ infusion of $\left[3-{ }^{3} \mathrm{H}\right]$-glucose (DuPont-NEN, Boston, Mass., USA) was administered for $2 \mathrm{~h}$. Blood $(50 \mu \mathrm{l})$ was sampled at time 0,10, 20, 30 and $40 \mathrm{~min}$. This later time $(40 \mathrm{~min})$, is the time at which a steady-state for $\left[3-{ }^{3} \mathrm{H}\right]$-glucose specific activity was reached (data not shown) and used for the determination of glucose turnover rate as described previ- ously [13]. Then, 2-deoxy-[1- $\left.{ }^{14} \mathrm{C}\right]$-glucose $(15 \mu \mathrm{Ci})$ was injected as a bolus into the saphenous vein. Blood was sampled via the arterial catheter at 1, 3, 5, 10, 20, 30 and 45 min after the 2-deoxy- $\left[1-{ }^{14} \mathrm{C}\right]$-glucose injection for determination of blood 2-deoxy-[1- $\left.{ }^{14} \mathrm{C}\right]$-glucose radioactivity and glucose concentrations (Boehringer Peridochrom Kit, Mannheim, Germany). After the final blood sample, the rat was killed. Soleus, extensor digitorum longus and epitrochlearis muscles were immediately removed and their 2-deoxy-[1- $\left.{ }^{14} \mathrm{C}\right]$-glucose-6-phosphate content was determined. The glucose utilization rate in each muscle was then calculated from the amount of tissue 2deoxy-[1-14C]-glucose-6-phosphate content and blood 2deoxy-[1-14C]-glucose [14]. In rats, these three muscles contain substantially different proportions of fibre types: the soleus muscle contains $16 \%$ fast oxidative glycolytic fibres and $84 \%$ slow oxidative fibres, the extensor digitorum longus (EDL) consists of $59 \%$ pale fast-twitch oxidative glycolytic fibres, $38 \%$ fast glycolytic fibres and $3 \%$ slow oxidative fibres [15, $16]$; the epitrochlearis consists of $65 \%$ fast-twitch glycolytic fibres, $20 \%$ fast-twitch oxidative and $15 \%$ slow-twitch oxidative fibres [17].

In the groups studied under insulin-stimulated conditions, a similar primed-continuous $\left[3-{ }^{3} \mathrm{H}\right]$-glucose as that described above was performed. At the start of the $\left[3-{ }^{3} \mathrm{H}\right]$-glucose infusion, a continuous porcine insulin (Actrapid, Novo Industry, Copenhagen, Denmark) infusion at $0.4 \mathrm{U} \cdot \mathrm{h}^{-1} \cdot \mathrm{kg}^{-1}$ for control rats and $0.5 \mathrm{U} \cdot \mathrm{h}^{-1} \cdot \mathrm{kg}^{-1}$ for pioglitazone-treated rats was initiated [13]. Different insulin infusion rates were used in the two groups since basal insulin concentrations are decreased twofold after the pioglitazone treatment. At 5 min time intervals, $10 \mu \mathrm{l}$ of blood were sampled and blood glucose measured. A variable infusion of $10 \%$ (wt/vol) glucose for control rats and $20 \%$ (wt/ vol) for pioglitazone-treated rats was adjusted to maintain the plasma glucose concentration at their basal glycaemia. Plasma samples for insulin were collected at $0,40,70$ and $85 \mathrm{~min}$. Steady-state conditions for blood glucose, plasma $\left[3-{ }^{3} \mathrm{H}\right]$-glucose specific activity and plasma insulin were reached within $40 \mathrm{~min}$ after initiation of $\left[3-{ }^{3} \mathrm{H}\right]$ glucose and insulin infusion (data not shown). The 2-deoxy-[1-14C]glucose experiment was then performed as described above in order to measure muscle glucose utilization under insulin stimulation.

RNA extraction and northern blot analysis. Obese Zucker fa/fa rats were treated or not with pioglitazone during 28 days as described above. Their muscles were then sampled and immediately frozen in liquid nitrogen.

Total cellular RNAs were extracted using a guanidine thiocyanate method [18]. RNA concentrations were measured spectrophotometrically (A260). Total RNAs (15 $\mu \mathrm{g})$ were denatured by heating at $95^{\circ} \mathrm{C}$ for $3 \mathrm{~min}$. RNAs were size fractionated on $1 \%$ (wt/vol) agarose gel containing $2.2 \mathrm{~mol} / \mathrm{l}$ formaldehyde in $20 \mathrm{mmol} / 13$-(N-morpholino)-propanesulfonic acid ( $\mathrm{pH} 7.0$ ), $50 \mathrm{mmol} / \mathrm{l}$ sodium acetate, and $1 \mathrm{mmol} / \mathrm{l}$ EDTA, by electrophoresis for 16-18 h at $50 \mathrm{~V}$. RNA were then transferred to a nylon membrane (Hybond-N, Amersham Life Science, Bucks, UK) and were cross-linked to membranes with UV lights before hybridization. The cDNA probes were labelled by primer extension with $\alpha\left[{ }^{32} \mathrm{P}\right] \mathrm{dCTP}$, using a labelling system kit (Rediprime, Amersham, Bucks, UK). Autoradiograms were obtained by exposure of radioactive nylon membranes to Hyperfilm MP (Amersham) at $-80^{\circ} \mathrm{C}$ with intensifying screens (Cronex, Du Pont, Paris, France).

cDNA probes. The cDNA for rat fatty acid synthase (FAS), phosphoenolpyruvate carboxykinase (PEPCK) and $\mathrm{C} / \mathrm{EBP} \alpha$ were as described previously [12]. $\mathrm{C} / \mathrm{EBP} \alpha$ is a transcription factor present in adipose tissue but not in muscle [19]. The my- 
Table 1. Glucose metabolism and insulin concentrations in the basal state or during a euglycaemic hyperinsulinaemic clamp

\begin{tabular}{lccl}
\hline & Control & Pioglitazone & $p$ value \\
\hline BBglc $(\mathrm{mg} / \mathrm{dl})$ & $85 \pm 4$ & $75 \pm 3$ & $p<0.05$ \\
BPins $(\mathrm{nmol} / \mathrm{l})$ & $1.7 \pm 0.3$ & $0.9 \pm 0.1$ & $p<0.05$ \\
BGTR & & & \\
$\left(\mathrm{mg} \cdot \mathrm{min}^{-1} \cdot \mathrm{kg}^{-1}\right)$ & $8.3 \pm 0.4$ & $9.5 \pm 0.5$ & NS \\
SSBG $(\mathrm{mg} / \mathrm{dl})$ & $93 \pm 3$ & $88 \pm 3$ & NS \\
SSPI $(\mathrm{nmol} / \mathrm{l})$ & $5.4 \pm 0.3$ & $6.3 \pm 0.4$ & NS
\end{tabular}

SSGTR

$\left(\mathrm{mg} \cdot \mathrm{min}^{-1} \cdot \mathrm{kg}^{-1}\right) \quad 12.5 \pm 1.3 \quad 24.3 \pm 1.3 \quad p<0.001$

Values are means \pm SEM, with eight animals in each experimental group. $p$ value indicates significance of the difference when compared to control. Studies in the basal state: BBglc: basal blood glucose; BPins: basal plasma insulin; BGTR: basal glucose turnover rate. Studies during the euglycaemic hyperinsulinaemic clamp: SSBG: steady state blood glucose; SSPI: steady state plasma insulin; SSGTR: steady state glucose turnover rate

ogenin probe was a kind gift from Dr C. Dani (Nice, France). Each northern-blot was hybridized with a ribosomal $18 \mathrm{~S}$ cDNA in order to verify that equivalent amounts of total RNA were loaded in each lane.

Statistical analysis. Statistical significance of differences was assessed using the Student's $t$-test for unpaired data.

\section{Results}

Pioglitazone improves overall insulin sensitivity in obese Zucker fa/fa rats. The treatment with pioglitazone induced a small decrease in basal blood glucose whereas basal insulin was markedly decreased (Table 1). Basal glucose turnover rate was slightly, but not significantly, increased by the pioglitazone treatment (Table 1). During the clamp studies high and non-significantly different concentrations of plasma insulin were achieved in the two groups of rats (Table 1). Insulin-stimulated glucose turnover rate was increased twofold in the pioglitazone-treated group (Table 1).

Glucose utilization rate in various muscles in the basal state and during the euglycaemic hyperinsulinaemic clamp. In the basal state, pioglitazone treatment increased glucose utilization only slightly in the soleus, an oxidative muscle (Fig. 1).

A high insulin concentration increased the glucose utilization rate in the muscles of both experimental groups. However, this increase was much larger in the pioglitazone-treated group (Fig.1). Interestingly enough, there was no difference in the stimulation of glucose utilization among the three muscles studied. This experiment underlines the major role of muscles in the improved glucose tolerance under pioglitazone treatment in the obese Zucker fa/fa rat.

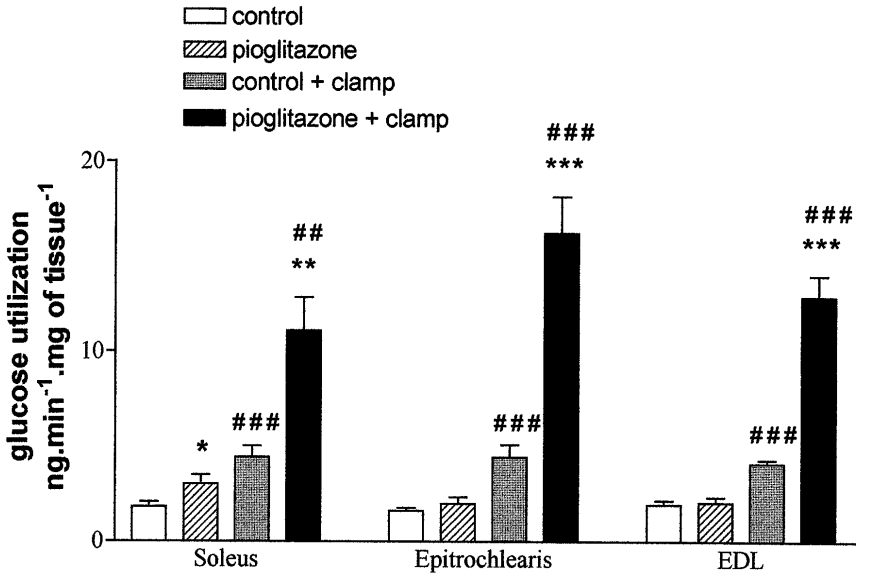

Fig. 1. Effect of pioglitazone treatment on glucose utilization in the soleus, epitrochlearis and EDL muscles in the basal state and during a euglycaemic hyperinsulinaemic clamp in the obese Zucker fa/fa rat. Data are expressed as means \pm SEM with eight animals in each experimental group. $* p<0.05$, $* * p<0.01$, *** $p<0.001$ for pioglitazone-treated vs control; $\# \# p<0.01, \# \# \#<0.001$ for clamp vs basal state

Adipose tissue differentiation is present only in the soleus muscle. We have then measured the expression of two genes (FAS and PEPCK) involved in lipid storage which are only expressed in mature adipocytes and not in muscles. In epitrochlearis and EDL muscles, FAS and PEPCK mRNAs were not detected in rats treated or not with pioglitazone, even after extensive exposures of the blots (results not shown). The presence of $\mathrm{C} / \mathrm{EBP} \alpha$ mRNA also could not be detected in these muscles (results not shown). In contrast, in the soleus muscle, FAS mRNA could be detected even in the control group, suggesting the presence of some adipose tissue in this oxidative muscle. Moreover, after the pioglitazone treatment, there was a clear-cut increase in FAS, PEPCK and $\mathrm{C} /$ $\mathrm{EBP} \alpha$ mRNAs (Fig.2), indicating the existence of an adipose tissue differentiation in the soleus.

In in vitro experiments, TZD, when inducing the conversion of myoblasts into adipocyte-like cells, strongly decreased the expression of myogenin, a transcription factor involved in the execution of the myogenic differentiation programme. If there was an important conversion of myoblasts into adipose tissue in the soleus muscle, then a decreased expression of myogenin could be anticipated. The expression of this gene was not affected by the pioglitazone treatment in the soleus (Fig.3) or in the epitrochlearis muscles (data not shown).

\section{Discussion}

As previously described in humans and animal models of insulin resistance, pioglitazone is able to improve insulin sensitivity of glucose-utilizing tissues 


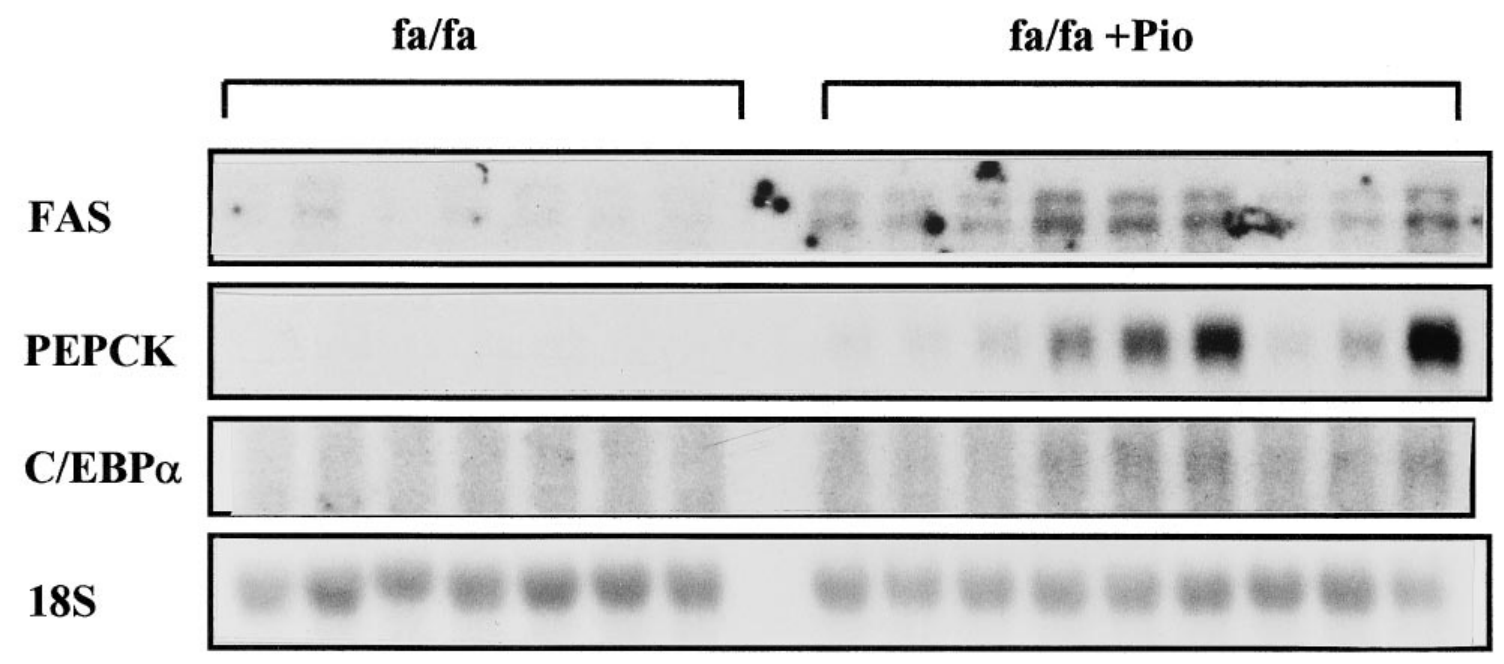

Fig. 2. Effects of pioglitazone treatment on FAS, PEPCK, and $\mathrm{C} / \mathrm{EBP} \alpha$ expression in the soleus muscle as analysed by northern-blotting. Pioglitazone was given orally to 12 -week-old female Zucker fa/fa rats for 28 days. Each lane represents a different animal ( $n=7$ for the Zucker fa/fa rats (fa/fa) and 9 for the pioglitazone-treated Zucker fa/fa rats $(\mathrm{fa} / \mathrm{fa}+\mathrm{Pio})$ )

markedly. In the post-absorptive state, we have shown previously in obese Zucker fa/fa rats that adipose tissue is the main tissue increasing its glucose utilization under TZD treatment [12].

In contrast, during insulin stimulation, we show that muscles play also an important role in the increased glucose turnover rate. This can be explained by the difference in insulin sensitivity of these two tissues, with adipose tissue being more sensitive to the hormone than muscles [20]. Here we show that under insulin stimulation muscle fibre composition does not markedly affect the TZD-induced increase of glucose utilization in a highly insulin-resistant animal model. This suggests that oxidative muscle metabolism is not the primary target of TZD action. This is reminiscent of what was observed in rats in which a moderate insulin resistance

Fig. 3. Effects of pioglitazone treatment on myogenin mRNA in soleus muscle. Pioglitazone was given orally to 12 -week-old female Zucker fa/fa rats for 28 days. Each lane represents a different animal ( $n=7$ for the Zucker fa/fa rats (fa/fa) and 9 for the pioglitazone-treated Zucker fa/fa rats (fa/fa + Pio)).The blot presented is the same as that used in Fig. 2 was induced by fat feeding and treated with ciglitazone [21].

The only well described mechanism of TZD action is linked to their binding and subsequent activation of $\operatorname{PPAR} \gamma$ leading to adipocyte differentiation both in vivo and in vitro. The physiological importance of $\operatorname{PPAR} \gamma$ in muscles is controversial. In rodents a very small expression of this factor was found in muscles [22]. In human muscles, the expression of PPAR $\gamma$ is also extremely small when compared with its expression in adipose tissue [23, 24]. However, even a small amount of PPAR $\gamma$ seems to be sufficient to induce the conversion of mouse satellite muscle cells into adipocytes as shown by in vitro experiments [11].

In the present in vivo study, we show clearly that no adipocyte markers could be detected before and after pioglitazone treatment in muscles which do not possess amounts of adipose tissue (EDL and epitrochlearis muscles) which were previously detectable and hence that a similar TZD-induced phenomenon does not exist in vivo. We cannot exclude that adipocyte accumulation may occur in these muscles for a longer TZD treatment. An adipose tissue differentiation is only detectable in the soleus, in which adipose tissue is present before TZD treatment. Only in soleus muscle could a TZD-increased glucose utilization be detected in the post-absorptive state. This could be due to the presence of an increased amount of highly insulin-sensitive adipose tissue. Finally, appearance of newly differentiated adipocytes in the soleus is not concomitant with a decreased expression of myogenin, a muscle specific transcription factor, as described previously in vitro [25]. Nevertheless, these experiments do not totally rule out the possibil-

$\mathbf{f a} / \mathbf{f a}$

fa/fa + Pio

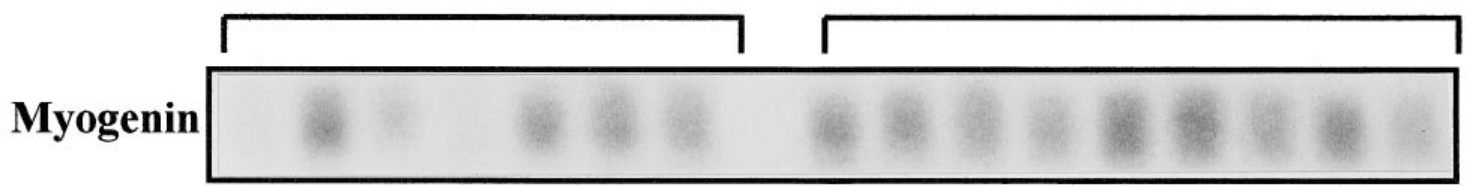


ity that the appearance of newly differentiated adipocytes in the soleus is linked to some myoblast transdifferentiation.

We concluded: (i) the conversion of myoblasts into adipocytes after a 4-week TZD treatment in vivo, if it exists, is a marginal phenomenon; (ii) the presence of PPAR $\gamma$ mRNA in muscles must be interpretated cautiously due to the potential contamination by mature adipocytes or even preadipocytes if subsequent cultures are performed; (iii) an increased amount of adipose tissue in muscles cannot explain their increased insulin sensitivity for glucose utilization. Indeed, although this increase is similar in the three muscles studied, the soleus is the only one in which adipose tissue differentiation is present. Moreover, the amount of adipose tissue in the soleus after TZD treatment is probably modest since, for a similar amount of total RNA on Northern-blots, the appearance of a signal for FAS and PEPCK cDNA probes requires only $24 \mathrm{~h}$ of film exposure in white adipose tissue [12] but at least 1 week in the soleus muscle.

Agents of the thiazolidinedione family are potent insulin sensitizers used at present to improve insulin sensitivity in Type II diabetes mellitus. If their action is exclusively through PPAR $\gamma$, then (i) one possibility is that the small amount of PPAR $\gamma$ in muscles [22] (see above) is sufficient to induce changes in gene expression favouring insulin action, (ii) if their action is restricted to adipose tissue, they could modulate the secretion of circulating insulin agonists or antagonists or both by adipose tissue. TNF $\alpha$ or leptin or both could then be obvious candidates although the existence of a still unknown factor cannot be excluded. $\mathrm{TNF} \alpha$ has been implicated in the insulin resistance of obesity and Type II diabetes mellitus [26, 27] and TZD are able to normalize the overexpression of $\mathrm{TNF} \alpha \mathrm{mRNA}$ and prevent $\mathrm{TNF} \alpha$-induced insulin resistance $[28,29]$. Leptin seems also to have an anti-insulin effect [30] and TZD are able to decrease leptin mRNA expression $[12,31]$, (iii) finally, as described recently for leukotriene B4 [32], TZD not only could bind to the nuclear receptor PPAR $\gamma$ but also to a membrane receptor present in muscles, mediating the insulin sensitizing process. This later possibility is re-enforced by the recent demonstration that in a mouse model of genetically ablated adipose tissue, troglitazone can still improve the diabetic state [33].

Acknowledgements. Sophie Hallakou has a grant from Lipha laboratories (Chilly-Mazarin, France). We thank Dr C. Dani for kindly providing myogenin plasmid used in northern experiments and F. Mouveaux and A.-M. Loiseau for skillful technical assistance.

\section{References}

1. Suter SL, Nolan JJ, Wallace P, Gumbiner B, Olefsky J (1992) Metabolic effects of new oral hypoglycemic agent CS-045 in NIDDM subjects. Diabetes care 15: 193-203

2. Nolan JJ, Ludvik B, Beerden P, Joyce M, Olefsky J (1994) Improvement in glucose tolerance and insulin resistance in obese subjects treated with troglitazone. N Engl J Med 3: 1188-1193

3. Bowen L, Steven PP, Stevenson R, Shulman CI (1991) The effect of CP-68772, a thiazolidine derivative, on insulin sensitivity in lean and obese Zucker rats. Metabolism 40: 1025-1030

4. Lehmann JM, Moore LB, Smith-Oliver TA, Wilkinson WO, Willson TM, Kliewer SA (1995) An antidiabetic thiazolidinedione is a high affinity ligand for peroxisome proliferator-activated receptor $\gamma$. J Biol Chem 270: 12953-12956

5. Tontonoz P, Hu E, Graves RA, Budavari AI, Spiegelman B (1994) mPPAR $\gamma 2$ : tissue-specific regulator of an adipocyte enhancer. Genes Dev 8: 1224-1234

6. Chawla A, Schwarz EJ, Dimaculangan DD, Lazar MA (1994) Peroxisome proliferator-activated receptor (PPAR) $\gamma$ : adipose-predominant expression and induction early in adipocyte differentiation. Endocrinology 135: 798-800

7. Sandouk T, Reda D, Hofmann C (1993) Antidiabetic agent pioglitazone enhances adipocyte differentiation of 3T3F442A cells. Am J Physiol 264:C1600-C1608

8. Tontonoz P, Hu E, Devine J, Beale EG, Spiegelman B (1995) PPAR $\gamma 2$ regulates adipose expression of the phosphoenolpyruvate carboxykinase gene. Mol Cell Biol 15: 351-357

9. Tontonoz P, Hu E, Spiegelman B (1994) Stimulation of adipogenesis in fibroblasts by PPARg2, a lipid-activated transcription factor. Cell 79: 1147-1156

10. Hu E, Tontonoz P, Spiegelman B (1995) Transdifferentiation of myoblasts by the adipogenic transcription factors PPAR $\gamma$ and C/EBP $\alpha$ Proc Natl Acad Sci (USA) 92: 9856-9860

11. Teboul M, Gaillard D, Staccini L, Inadera H, Amri E-Z, Grimaldi P (1995) Thiazolidinediones and fatty acids convert myogenic cells into adipose-like cells. J Biol Chem 270: 28183-28187

12. Hallakou S, Doaré L, Foufelle F, Kergoat M, Guerre-Millo M, Berthault M-F et al. (1997) Pioglitazone induces in vivo adipocyte differentiation in the obese Zucker fa/fa rat. Diabetes 46: 1393-1399

13. Burnol A-F, Leturque A, Ferré P, Girard J (1983) A method for quantifying insulin sensitivity in vivo in the anesthetized rat: the euglycemic insulin clamp technique coupled with isotopic measurement of glucose turnover. Reprod Nutr Dev 23: 429-435

14. Ferré P, Leturque A, Burnol A-F, Pénicaud L, Girard J (1985) A method to quantify glucose utilization in vivo in skeletal muscle and white adipose tissue of the anesthetized rat. Biochem J 228: 103-110

15. Goldberg AL, Martel SB, Kushmerick MJ (1975) In vitro preparations of the diaphragm and other skeletal muscles. Methods Enzymol 39: 82-94

16. Ariano MA, Armsrtrong RB, Edgerton VR (1973) Hindlimb muscle fiber populations of five mammals. J Histochem Cytochem 21: 51-55

17. Nesher H, Karl IE, Kaiser KE, Kipnis DM (1980) Epitrochlearis muscle.I. Mechanical performance energetics on fiber composition. Am J Physiol 239:E454-E460 
18. Chomczynski P, Sacchi N (1987) Single-step method of RNA isolation by acid guanidium thiocyanate-phenolchloroform extraction. Anal Biochem 162: 156-159

19. Calkhoven CF, ABG (1996) Multiple steps in the regulation of transcription-factor level and activity. Biochem $\mathrm{J}$ 317: 329-342

20. Kraegen EW, James DE, Jenkins AB, Chisholm DJ (1985) Dose-response curves for in vivo insulin sensitivity in individual tissues in rats. Am J Physiol 248:E353-E362

21. Kraegen EW, James DE, Jenkins AB, Chisholm DJ, Storlien LH (1989) A potent in vivo effect of ciglitazone on muscle insulin resistance induced by high fat feeding of rats. Metabolism 38: 1089-1093

22. Vidal-Puig A, Jimenez-Linan M, Lowell BB, Hamann A, $\mathrm{Hu}$ E, Spiegelman B et al. (1996) Regulation of PPAR $\gamma$ gene expression by nutrition and obesity in rodents. J Clin Invest 97: 2553-2561

23. Fajas I, Auboeuf D, Raspé E, Schoonjans K, Lefebvre AM, Saladin R et al. (1997) The organization, promoter analysis, and expression of the human PPAR $\gamma$ gene. J Biol Chem 272: 18779-18789

24. Auboeuf D, Rieusset J, Fajas I, Vallier P, Frering V, Riou JP et al. (1997) Tissue distribution and quantification of the expression of mRNAs of peroxisome proliferator-activated receptors and liver X receptor- $\alpha$ in humans. Diabetes 46: 1319-1327

25. Buckingham M (1992) Making muscle in mammals. Trends Genet 8: 144-148

26. Hotamisligil G, Shargill NS, Spiegelman B (1993) Adipose expression of tumor necrosis factor- $\alpha$ : direct role in obesity-linked insulin resistance. Science 259: 87-91
27. Peraldi P, Spiegelman B (1997) TNF- $\alpha$ : lien moléculaire entre obésité et résistance à l'insuline; In: journées de diabétologie; Flammarion Médecine-sciences France, pp 149-159

28. Hofmann C, Lorenz K, Braithwaite SS, Colca JR, Palazuk BJ, Hotamisligil GS et al. (1994) Altered gene expression for tumor necrosis factor- $\alpha$ and its receptors during drug and dietary modulation of insulin resistance. Endocrinology 134: 264-270

29. Miles PDG, Romeo OM, Higo K, Cohen A, Rafaat K, Olefsky JM (1997) TNF- $\alpha$-induced insulin resistance in vivo and its prevention by troglitazone. Diabetes 46: 1678-1683

30. Müller G, Ertl J, Gerl M, Preibisch G (1997) Leptin impairs metabolic actions of insulin in isolated rat adipocytes. J Biol Chem 272: 10585-10593

31. De Vos P, Lefebvre A-M, Miller SG, Guerre-Millo M, Wong K, Saladin R et al. (1996) Thiazolidinediones repress ob gene expression in rodents via activation of peroxisome proliferator-activated receptor $\gamma$. J Clin Invest 98: 1004-1009

32. Yokomizo T, Izumi T, Chang K, Takuma Y, Shimizu T (1997) A G-protein-coupled receptor for leukotriene B4 that mediates chemotaxis. Nature 387: 620-624

33. Burant CF, Sreenan S, Hirano K-I, Tai T-AC, Lohmiller J, Lukens J et al. (1997) Troglitazone action is independent of adipose tissue. J Clin Invest 100: 2900-2908 